\title{
Práticas de visitação nas vinícolas da Serra Gaúcha: unindo vitivinicultura e turismo no sul do Brasil
}

\author{
Virgínia Aparecida Castro ${ }^{a}$ \\ Glauber Eduardo de Oliveira Santos ${ }^{b}$ \\ Maria Henriqueta Sperandio Garcia Gimenes-Minasse \\ Janaina de Moura Engracia Giraldi ${ }^{d}$
}

\section{Resumo}

No Brasil, o enoturismo surgiu como atividade regular a partir da década de 1990 e desde então tem crescido rapidamente. A principal região produtora de vinho e receptora de enoturistas no país é a Serra Gaúcha, no Rio Grande do Sul. Este artigo objetiva descrever as práticas de visitação turística das vinícolas da Serra Gaúcha com particular atenção em questões relacionadas ao histórico da visitação, à estrutura e organização receptiva, aos roteiros de visitação, aos produtos e serviços complementares, à comunicação e promoção, e à quantidade e perfil dos visitantes das vinícolas. Tais objetivos foram alcançados por meio de uma revisão bibliográfica, pesquisa documental e realização de entrevistas semiestruturadas com gestores de vinícolas que recebem visitantes, totalizando consultas a 14 propriedades. 0 trabalho revela o sucesso da atividade enoturística na Serra Gaúcha e detalhes sobre como tais resultados são alcançados. A simbiose entre turismo e a vitivinicultura é apontada como um dos principais fatores.

Palavras-chave: Enoturismo; Vinho; Vinícolas, Serra Gaúcha, Brasil

\section{Abstract \\ Visitation practices in the wineries of Serra Gaúcha: winemaking and tourism in South Brazil}

Wine tourism in Brazil has grown rapidly since its introduction as a regular activity in the beginning of the 1990's. The leading winemaking and enotourism region in the country is Serra Gaúcha. This paper aims to describe the tourism visitation practices of the wineries of Serra Gaúcha with particular attention to issues related to the history of visitation, receptive structures and organization, visitation itineraries, complementary products and services, communication and promotion, number and profile of visitors. These objectives were achieved through literature review, documental research and qualitative interviews with managers of 14 wineries that are visited. The paper reveals the success of the enotourism in Serra Gaúcha and details about how this outcome is

a. Doutorado em Administração e professora pela Faculdade de Economia, Administração e Contabilidade de Ribeirão Preto, Universidade de São Paulo (FEA-RP/USP). Ribeirão Preto, São Paulo, Brasil. E-mail: virginiaconsultoria@yahoo.com.br

b. Doutorado em Economia do Turismo e do Meio Ambiente (Universitat de les Illes Balears) Espanha. Doutorado em Administração de Organizações (FEA-RP/USP). Professor pela Escola de Artes, Ciências e Humanidades da Universidade de São Paulo (EACH-USP). São Paulo, São Paulo, Brasil. E-mail: glauber.santos@usp.br

c. Doutorado em História pela Universidade Federal do Paraná (UFPR). Professora pela Universidade Anhembi Morumbi. São Paulo, São Paulo, Brasil. E-mail: mariegimenes@gmail.com

d. Master of Science in Marketing pela Katholieke Universiteit Leuven (KULeuven) Bélgica. Livre Docente pela Faculdade de Economia, Administração e Contabilidade de Ribeirão Preto, Universidade de São Paulo (FEA-RP/USP). Ribeirão Preto, São Paulo, Brasil. E-mail: jgiraldi@usp.br 
being obtained. The symbiosis between tourism and wine production is highlighted as one of the main contributing factors.

Keywords: Enotourism,; Wine; Tourist visitation; Wineries, Brazil.

\section{Resumen}

Prácticas de visitación en las bodegas de Serra Gaúcha: vinicultura y turismo en el sur de Brasil

En Brasil el enoturismo se ha convertido en una actividad regular en la década de 1990 y desde entonces ha crecido rápidamente. La principal región productora de vino y destino de enoturistas en el país es la Serra Gaúcha en Rio Grande do Sul. Este artículo tiene como objetivo describir las prácticas de visitación turística de bodegas en Serra Gaúcha, con especial atención a los temas relacionados con la historia de la visitación, la estructura y la organización de receptiva, los itinerarios de visita, los productos y servicios complementarios, la comunicación y la promoción, y la cantidad y perfil de los visitantes a las bodegas. Estos objetivos se logran a través de una revisión de la literatura, investigación documental y realización de entrevistas semi-estructuradas con los gerentes de 14 bodegas que reciben a los visitantes. El trabajo revela el éxito de la actividad enoturística en Serra Gaúcha y detalles sobre cómo se logran esos resultados. La simbiosis entre el turismo y la industria del vino es visto como un factor importante para tanto.

Palabras clave: Enoturismo; Vino; Bodegas, Serra Gaúcha, Brasil

\section{INTRODUÇÃo}

As raízes do vinho na civilização ocidental são antigas e evidentes. 0 vinho é parte integrante da alimentação, cultura, economia e sociedade em diversos países. 0 interesse por essa bebida motiva inúmeras atividades, incluindo compras, estudos, eventos, viagens e outras. Em especial, a relevância do vinho como motivador de viagens turísticas, o chamado enoturismo, tem sido amplamente notada e discutida (Carlsen \& Charters, 2006; Croce \& Perri, 2010; Hall, 2003; Hall, Sharples, Cambourne, \& Macionis, 2000; Peris-Ortiz, Rama, \& Rueda-Armengot, 2015).

O enoturismo já pode ser considerado uma atividade tradicional em alguns países europeus, como França, Itália, Espanha e Portugal. Nas últimas décadas, essa atividade tem alcançado novas regiões do planeta, passando a ocorrer em diversos países de colonização europeia, como Estados Unidos, Austrália, Nova Zelândia, África do Sul, Chile, Argentina e Brasil. Nas terras brasileiras, o enoturismo surgiu como atividade regular a partir da década de 1990 e desde então tem crescido rapidamente, sendo a principal região produtora de vinho e receptora de visitantes a Serra Gaúcha, no Rio Grande do Sul.

A realidade e as práticas do enoturismo ao redor do mundo são diversas: estruturas, atividades e perspectivas apresentam variações resultantes do ajuste do segmento às condições locais e das inovações que oferecem ganhos de qualidade e eficiência para empresas e consumidores. Considerada a importância da Serra Gaúcha para a vinicultura e o enoturismo brasileiros, a descrição sistemática da realidade e das práticas existentes nessa região pode ser entendida como 
a principal contribuição brasileira para o painel de experiências mundiais neste campo.

Apesar da relevância deste tema, a literatura nacional existente é relativamente pequena e dispersa. Os poucos estudos existentes sobre o enoturismo na Serra Gaúcha tratam essencialmente de aspectos históricos, culturais e organizacionais (Costa, 2010; Lavandoski, Tonini, \& Barretto, 2012; Marques \& Santos, 2012; Silva, 2008; Tonini, 2007; Tonini \& Lavandoski, 2011; Valduga, 2007, 2012; Valduga \& Valduga, 2016; Zanini, 2007; Zanini \& Rocha, 2010). Contudo, a disponibilidade de descrições sistemáticas das práticas de visitação das vinícolas da Serra Gaúcha é muito restrita.

Em busca de preencher esta lacuna, o presente estudo objetivou descrever as práticas de visitação turística das vinícolas localizadas na Serra Gaúcha. Os objetivos específicos do trabalho foram descrever questões relacionadas ao histórico da visitação, à estrutura e organização receptiva, aos roteiros de visitação, aos produtos e serviços complementares, à comunicação e promoção, e à quantidade e perfil dos visitantes das vinícolas. Para alcançá-los, foi realizada uma pesquisa documental sobre a realidade enoturística da região, uma pesquisa bibliográfica para discutir conceitos relacionados ao enoturismo, bem como identificar trabalhos focados na região estudada, e entrevistas semiestruturadas com gestores de 14 vinícolas que já operam com enoturismo na região.

\section{ENOTURISMO: CONCEITOS E PRINCÍPIOS}

Para Hall, Johnson, et al. (2000), as visitações a regiões produtoras de vinho já integravam os Gran Tours, viagens de caráter formativo destinadas a jovens de famílias ricas europeias que eram comuns entre os séculos XVII e XIX. Segundo Dallanhol e Tonini (2012), o desenvolvimento das rotas enoturísticas europeias data do início do século XX, com iniciativas ocorridas na Alemanha. França e Itália.

Existem diferentes conceitos de enoturismo vinculados na literatura acadêmica. Em uma definição bastante abrangente, Beames (2003) estabelece que o enturismo esta intrinsecamente relacionado a toda experiência que o viajante vivencia no contexto da produção vinícula. Já Hall, Johnson, et al. (2000, p. 3) definem o enoturismo como "[...]visitation to vineywards, wineries, wine festivals and wineshows for which grape, wine tasting and/or experiencing the attributions of a grape wine region are the prime motivating factor for visitors". Buscando construir uma conceituação mais abrangente, Valduga $(2007$, p. 16) caractriza o enoturismo como:

Um segmento do fenômeno turístico, que pressupõe deslocamento de pessoas, motivadas pelas propriedades organolépticas e por todo o contexto da degustação e elaboração de vinhos, bem como a apreciação das tradições, de cultura, gastronomia, das paisagens e tipicidades das regiões produtoras. É um fenômeno dotado de subjetividade, em que a principal substância é o encontro com quem produz uvas e vinhos. 
Trata-se, portanto, de uma forma de consumo complexo da paisagem e de um contexto cultural pois, como observa Gimenes (2012, p. 13), "o enoturismo articula uma série de atrativos [...] seja em termos da paisagem natural local, seja em termos de ambientação criada para a produção do vinho e para o acolhimento dos turistas, seja por meio dos sabores degustados criados a partir do local de produção", podendo envolver assim diferentes motivações.

Estas motivações, inclusive, podem não estar relacionadas diretamente ao consumo de vinhos, mas orientadas para as paisagens dos parrerais e ao clima rural proporcionado pelas regiões produtoras. Por exemplo, em uma pesquisa sobre o distrito australiano de Canberra, Mitchell, Hall e McIntosh (2000) identificaram que além das motivações relacionadas diretamente ao consumo da bebida, a participação em festivais e eventos relacionados, entretenimento e socialização com amigos, encontro com o produtor e a possiblidade de desfrutar das regiões de produção eram também relevantes.

É nesta perspectiva que Dallanhol e Tonini (2012, p. 39) indicam que o enoturismo se desenvolve a partir de diferentes atividades que visam permitir ao turista "[...] fazer a visitação das vinícolas, conhecendo o processo de elaboração do vinho; realizar a degustação dos produtos; fazer compras no varejo; além de conhecer a gastronomia local e hospedar-se na região produtora".Desta forma, como observa Tonini (2007), o enoturismo pode ser caracterizando como um sistema que é influenciado tanto por aspectos individuais do visitante quanto pela oferta como um todo. Assim, no estudo da demanda enoturística devem ser consideradas características como referências culturais e percepção pessoal, uma união entre experiência passada, informações e preferências.

- Os visitantes de um mesmo atrativo enoturístico podem ter, além de diferentes interesses, diferentes níveis de conhecimento sobre vinho.Tratando dos perfis de visitantes, Charters e Ali-Knight (2002), a partir de uma pesquisa realizada na Austrália, propuseram quatro categorias de enoturistas:

- Amante do vinho (wine lover): visitantes que já possuem um bom conhecimento prévio sobre a bebida e possuem familiaridade com tema a partir de livros, programas de televisão, cursos, degustações prévias e visitas realizadas a outras regiões produtoras. A motivação é claramente centrada no aprendizado sobre o vinho e nas degustações oferecidas, além do usufruto do estilo de vida associado ao vinho. Tendem a ter menos interesse em atividades secundárias oferecidas pelas vinícolas.

- Conhecedor de vinhos (connoisseur): uma subcategoria da wine lover, com a distinção dos visitantes possuírem um interesse ainda mais específico pelo aprendizado proporcionado pela visita, em especial em relação a aspectos como a produção e degustação da bebida, além de aspectos concernentes às características das videiras.

- Interessado no vinho (wine interested): visitantes que podem ter participado de degustações e visitas a outras vinícolas, mas possuem pouco conhecimento prévio sobre o vinho e seu universo. A motivação é menos definida e parecem ter interesse principalmente em aprender como degustar vinhos, além de realizar compras, mas pouco interesse pela harmonização entre comida e bebida. 
- Novato do vinho (wine novice): visitantes que possuem pouco conhecimento prévio sobre o vinho e o seu universo e são mais propensos a participar de visitas gerais, demonstrando pouco interesse específico no processo de produção do vinho ou na percepção das características organolépticas da bebida. Tem interesse por um passeio mais ativo pela vinícola, ao invés de simplesmente provar vinhos na porta da adega.

Além destas categorias, Dallanhol e Tonini (2012) destacam a tipologia proposta por Johnson (1998), que identifica dois principais perfis de enoturistas: o especialista, que realiza as visitas como recreação, mas cuja motivação central está voltada para o interesse específico em alguma uva ou vinho; e o genérico, que busca recreação e relaxamento em um contexto enoturístico.Parte da diferenciação e da segmentação dos enoturistas se deve a questões puramente individuais. Entretanto, algumas diferenças estão associadas a questões demográficas e sociais, como idade, renda e ciclo de vida da família (Dawson, Holmes, Jacobs, \& Wade, 2011).

No estudo de Alonso, Fraser e Cohen (2007) foram investigadas as diferenças entre os visitantes nacionais e estrangeiros de vinícolas da Nova Zelândia, identificando-se que o consumidor doméstico se mostrou mais conhecedor de vinhos, enquanto os visitantes estrangeiros possuíamuma maior disposição em pagar preços mais altos pela garrafa de vinho. 0 enoturismo, neste sentido, conforma-se como um sistema que envolve diferentes sujeitos, que podem receber diferentes benefícios a partir de seu desenvolvimento. Gimenes (2012) observa que os consumidores têm a oportunidade de vivenciar novas e, possivelmente, marcantes experiências sensoriais e culturais em paisagens diferenciadas, em que podem tanto desfrutar da bebida e de suas possíveis harmonizações com alimentos, bem como da cultura do vinho em um sentido amplo, incluindo não só as degustações em si, mas também a possibilidade de acompanhar as diferentes etapas do ciclo produtivo.

No estudo de Mitchell e Hall (2003), verifica-se que, na Nova Zelândia, por exemplo, as visitas às vinícolas são sazonais e sofrem influências do fornecimento e demanda do vinho com preferências principalmente para o verão. Esta sazonalidade se deve aos aspectos de mercado como país de origem, nível de conhecimento do vinho, bem como sobre a região do vinho em termos de tráfego turístico. A sazonalidade traz como implicações para as vinícolas questões relacionadas ao fluxo de caixa e planejamento orçamentário. 0 impacto dependerá se a vinícola é altamente dependente da venda porta-a-porta ao turista ou se ela diversifica seus canais de distribuição, podendo superar os desafios advindos da sazonalidade.

A comunidade receptora, por sua vez, é favorecida pelo fortalecimento das instâncias da cadeia produtiva da vitivinicultura e pela atração de investimentos voltados para o atendimento dos visitantes, tais como restaurantes, meios de hospedagem e comércio em geral, o que termina por dinamizar outras esferas da economia local (Gimenes, 2012).Para a indústria vitivinicultora há também inúmeros benefícios, destacando-se o já mencionado fortalecimento de toda a cadeia produtiva do vinho, a oportunidade de incremento das vendas no varejo e o fortalecimento da marca, que se torna mais conhecida e competitiva. Inclusive, a presença de lojas nas vinícolas é um indício importante da complementação de renda, seja por conta da comercialização de outras bebidas produzidas na pro- 
priedade, produtos alimentares (como geleias, queijos, doces) ou ainda produtos associados ao universo do vinho, como taças, saca-rolhas, utensílios para serviço, aventais e congêneres. Muitos destes itens são personalizados e se constituem como memorabília, representando também uma importante estratégia de divulgação e fixação da marca.

Em um raciocínio semelhante, Dallanhol e Tonini (2012) observam que a indústria vinícola se apoia na prática turística - e na busca por conhecimento e descanso associada ao universo do vinho - para obter a vantagem da venda direta, já que os visitantes têm a oportunidade de degustar a bebida nas vinícolas e, caso apreciem, podem adquiri-las no próprio estabelecimento, sem a remuneração de intermediários. Para as autoras "a prática turística junto às regiões vitivinícolas é responsável por um incremento considerável nas vendas, auxiliando a divulgação do produto e fazendo com que os vitivinicultores redobrem esforços em busca de qualidade" (Dallanhol \& Tonini, 2012, p. 43).

Esta ideia da venda direta pode ser complementada por Mitchell et al. (2000) que mostram estudos na Nova Zelândia que apontam que quase $50 \%$ dos visitantes das vinícolas fizeram uma recompra no tempo de seis a oito meses após a visita. A fidelidade à marca foi apresentada entre os visitantes de certas regiões e vinícolas de médio e grande porte, bem como para visitantes domésticos e pessoas com avançado conhecimento sobre vinho e que bebem com mais frequência.

Uma vez apresentado o conceito e a importância do enoturismo, o próximo item aborda aspectos gerais do desenvolvimento dessa atividade no Brasil, destacando a produção vinícola e a organização do turismo de vinhos no país, dando atenção especial à região da Serra Gaúcha, lócus deste trabalho.

\section{VitiviniculturAe ENOTURISMO NO BRASIL}

A produção e o consumo de vinho no Brasil remontam ao início da colonização portuguesa. Contudo, a produção nacional foi até recentemente dominada por vinhos rústicos produzidos a partir de castas americanas e híbridas, como Isabel, Bordô e Niágara. Quase todo o consumo de vinhos finos foi suprido pela importação mas, no início da década de 1990, com a abertura do país ao mercado internacional, a indústria vitivinícola começou um lento processo de modernização em face da concorrência estrangeira (Farina \& Roloff, 2015). Nesse período,chegaram ao país algumas empresas multinacionais, como a Chandon e a Almadén, e os produtores começaram a investir em uvas viníferas europeias, como Cabernet Sauvignon, Merlot e Chardonnay. Além disso, evoluiu muito o conhecimento nacional sobre o processo de produção de vinhos, tanto através do intercâmbio com produtores argentinos, chilenos e europeus, quanto por meio de cursos relacionados à enologia.

Hoje, o Brasil tem 83,7 mil hectares de produção vitivinícola e mais de 1100 vinícolas (IBRAVIN, 2016b). 0 país ocupa a $19^{\circ}$ posição no ranking de paísespor área cultivada com uvas (mais de 82 mil hectares), a $12^{\circ}$ posição na produção de uvas (1,5 milhão de toneladas) e o $13^{\circ}$ lugar na produção de vinhos (350 mil toneladas).De 2004 a 2014 houve 100\% de crescimento da produção nacional de vinhos finos, passando de 25 milhões para 50 milhões de litros (Copello, 2015). Atualmente a produção de vinho é realizada em 13 estados brasileiros: Santa 
Catarina, Paraná, São Paulo, Minas Gerais, Espírito Santo, Rio de Janeiro, Goiás, Mato Grosso, Bahia, Pernambuco, Ceará, Maranhão e o Rio Grande do Sul (Copello, 2015)

No Planalto Catarinense há cerca de 150 rótulos de vinhos elaborados na região de São Joaquim (SC) como vinhos finos de altitude com ênfase na produção de Cabernet Sauvignon. Em 2014 havia em todo o estado uma área plantada de 4225 hectares de videiras, produzindo 11 milhões de litros de vinhos de mesa e 12 milhões de litros de vinhos finos. Na região de Urussanga (SC) a produção é das uvas de Goethe, uma casta híbrida utilizada para a produção de sucos e vinhos de mesa e que é registrada junto ao INPI como Indicação de Procedência. A região possui 40 hectares plantados e produz 750 mil litros de vinho de Goethe (Copello, 2015; Grizzo, Burgos \& Milan, 2014).

No Nordeste, a região do Vale do São Francisco entre os estados da Bahia e de Pernambuco tem uma produção vinícola recente. Contudo, o terroir ${ }^{1}$ diferenciado permitiu uma promissora produção das uvas Syrah, Touriga Nacional, Tempranillo e Petit Verdot. 0 Vale do São Francisco tem 370 hectares plantados e produz 3,5 milhões de litros de vinhos finos, dos quais 1,5 milhões de litros são espumantes moscatéis (Copello, 2015; Grizzo et al., 2014).

Existem ainda novos terroirs sendo estudados e trabalhados no Brasil, com destaque para o Sudeste e o Centro Oeste: os primeiros vinhos do Sudeste começaram a chegar ao mercado recentemente e ainda há muito para se descobrir sobre este terroir, e noCentro-Oeste, na região da Serra dos Pirineus (G0) iniciaram-se recentemente os primeiros empreendimentos vitivinicultores (Copello, 2015; Grizzo et al., 2014).

A região Sulé a principal produtora de vinhos no Brasil, com destaque para o Rio Grande do Sul. Com clima subtropical úmido, ele é responsável pela produção de cerca de $90 \%$ das garrafas disponíveis no mercado nacional. Ali existem quatro regiões produtoras de vinho: a Serra do Sudeste, os Campos de Cima da Serra, a Campanha Gaúcha e a Serra Gaúcha, descritas brevemente no Quadro 1:

Quadro 1 - Regiões produtoras de vinho no estado do Rio Grande do Sul.

\begin{tabular}{l|l}
\multicolumn{1}{c|}{ Região } & \multicolumn{1}{c}{ Principais características } \\
\hline $\begin{array}{l}\text { Serra do } \\
\text { Sudeste }\end{array}$ & $\begin{array}{l}\text { Com clima mais estável, é um dos novos terroirs e tem vinícolas importantes } \\
\text { como Chandon, Casa Valduga e Lídio Carraro. O terroir do município de } \\
\text { Encruzilhada do Sul é versátil e oferece resultados positivos para diferentes } \\
\text { uvas como Tempranillo, Touriga Nacional e Tannat. Entretanto, a vinificação } \\
\text { geralmente ocorre em Bento Gonçalves/RS (Farina \& Roloff, 2015; Grizzo et } \\
\text { al., 2014). }\end{array}$ \\
\hline $\begin{array}{l}\text { Campos de } \\
\text { Sima da }\end{array}$ & $\begin{array}{l}\text { Possui os invernos mais rigorosos e produz uvas em altitude como Merlot, } \\
\text { Cabernet Sauvignon, Chardonnay e Sauvignon Blanc. Tem um bom final de } \\
\text { maturação das uvas de colheita tardia (Farina \& Roloff, 2015; Grizzo et al., } \\
\text { 2014). }\end{array}$
\end{tabular}

(continua...)

1. Terroir: 0 termo faz referência à interação entre o meio natural e os fatores humanos, incluindo aspectos do meio natural (clima, solo, relevo), mas também, de forma simultânea, os fatores humanos da produção - incluindo a escolha das variedades, aspectos agronômicos e aspectos de elaboração dos produtos (TONIETTO, 2007). 
Quadro 1 - Continuação

\begin{tabular}{|l|l|}
\multicolumn{1}{c|}{ Região } & \multicolumn{1}{c}{ Principais características } \\
\hline Gampanha & $\begin{array}{l}\text { Com clima mais continental, com solo e temperatura favoráveis para produção } \\
\text { em larga escala. As uvas produzidas na região da Campanha geralmente } \\
\text { são vinificadas na Serra Gaúcha. Em } 2013 \text { foram produzido 5,23 milhões de } \\
\text { quilos de uvas viníferas e 3,86 milhões de litros de vinhos finos; as uvas de } \\
\text { mesa produziram 110 mil litros de sucos e derivados. Produzem Cabernet } \\
\text { Sauvignon, Merlot, Tannat, Pinot Noir, Tempranillo e Touriga Nacional, sendo } \\
\text { a Tannat muito bem adaptada à Campanha, onde é largamente produzida } \\
\text { (Copello, 2015; Grizzo et al., 2014). }\end{array}$ \\
\hline Serra Gaúcha & $\begin{array}{l}\text { Com clima úmido marcadamente europeu e solo ácido,destaca-se pela } \\
\text { produção de Chardonnay, Riesling Itálico e Pinot Noir. Em 2014 colheu } \\
\text { um total de 581 milhões de quilos de uva e elaborou 192 milhões de } \\
\text { litros de vinho de mesa e 34 milhões de litros de vinhos finos, com grande } \\
\text { destaque para os espumantes (em 2013 foram produzidos 15,8 milhões de } \\
\text { espumantes) (Copello, 2015; Grizzo et al., 2014). }\end{array}$
\end{tabular}

Fonte: elaboração própria.

A Serra Gaúcha é tida como o epicentro da produção vitivinícola brasileira, além de ser a região produtora mais tradicional. Apresentada na Figura 1,é composta por 47 municípios, tendo sofrido forte influência da imigração italiana entre a segunda metade do século XIX e a primeira metade do século XX; tendo recebido também núcleos de colonização alemã e polonesa. A região possui cinco registros junto ao INPI (Instituto Nacional de Marcas e Patentes) de Indicação Geográfica: Vale dos Vinhedos, Pinto Bandeira, Monte Belo do Sul, Altos Montes (Flores da Cunha) e Farroupilha. Todas estas regiões possuem Indicação de Procedência, sendo que o Vale dos Vinhedos além disto possui também Denominação de Origem. A região conta ainda com uma Marca Coletiva registrada no INPI que é o Consórcio de Produtores de Espumantes de Garibaldi (CPEG).

Figura 1- Mapa simplificado das regiões vitivinícolas do Rio Grande do Sul e Santa Catarina.

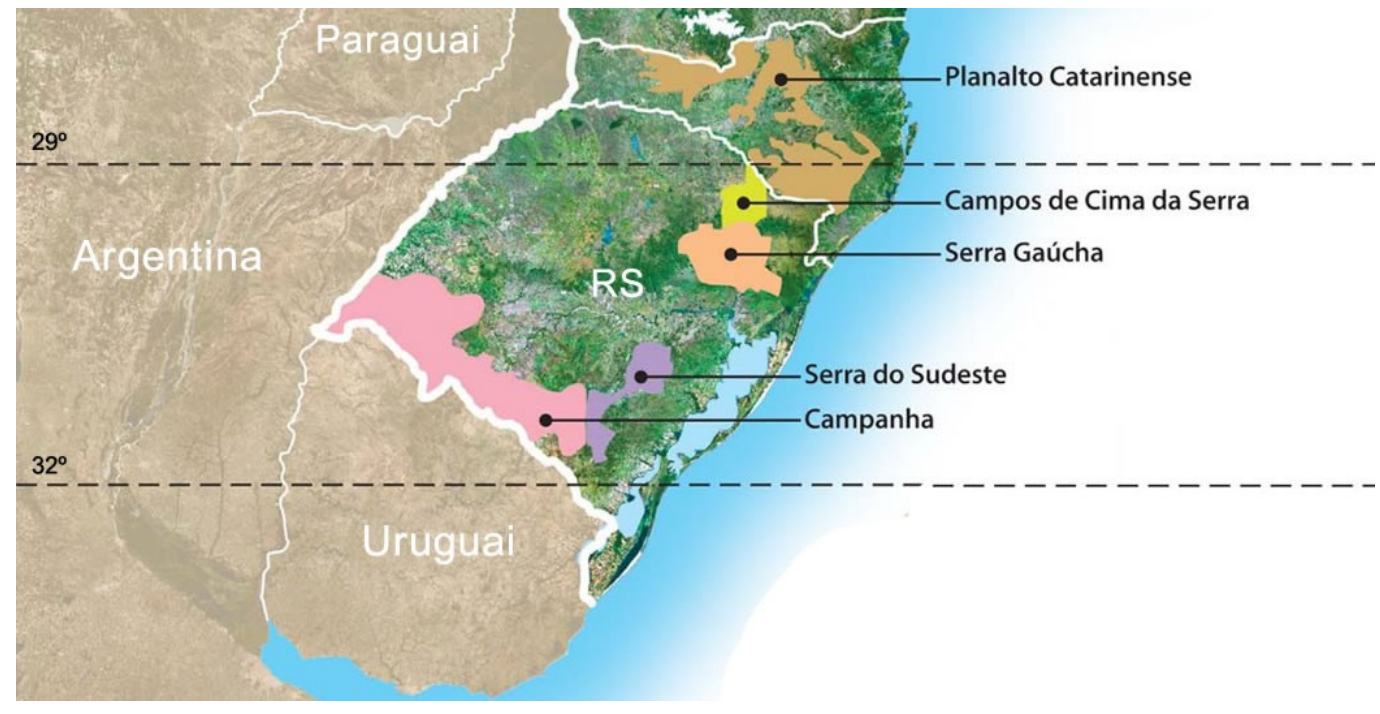

Fonte - IBRAVIN (2016a).

Em 2014, a Serra Gaúcha colheu 581 milhões de quilos de uva, sendo que destes 54 milhões foram de uvas vitis vinífera para a produção de vinhos finos e 
espumantes. As propriedades da Serra Gaúcha em geral não passam de 14 hectares, sendo minifúndios com herança da tradição dos antepassados e com mão-de-obra familiar. Os parreirais ocupam em média 2,6 hectares/propriedade com média de 4 moradores por propriedade. Ao todo, cerca de 57 mil pessoas trabalham nas vinícolas da região (Copello, 2015; Grizzo et al., 2014).

O enoturismo na Serra Gaúcha é uma atividade importante e consolidada (Chiattone \& Chiattone, 2013), que segundo Valduga (2007) teve início nas décadas de 1970 e 1980.0 mesmo autor sustenta que o desenvolvimento da atividade no Vale dos Vinhedos (sub-região da Serra Gaúcha formada pelos municípios de Bento Gonçalves, Garibaldi e Monte Belo do Sul) se deu com a abertura da comercialização de vinho finos diretamente em vinícolas como Vinícola Fontanive (já extinta) e a atual Casa Valduga. A associação da região com o universo do vinho foi fortalecida por eventos como Fenachamp (Festa da Champanha) em Garibaldi, da Fenavinho em Bento Gonçalves e da Festa da Uva em Caxias do Sul, bem como pela articulação e criação de cooperativas e associações(Valduga \& Valduga, 2016).

Em termos institucionais, Dallanhol e Tonini (2012) destacam a criação do Sindicato do Vinho em 1928 (com o objetivo de congregar e defender os interesses dos vitivinicultores, regulando a oferta e os preços); da Sociedade Vinícola Riograndense Ltda.em 1929 (criada como órgão comercial do Sindicato do Vinho, com o objetivo de melhorar a imagem e a reputação do vinho gaúcho em São Paulo e no Rio de Janeiro); da União Brasileira de Vitivinicultura (UVIBRA) em 1967 (fundada para reunir empresas e entidades setoriais da vitivinicultura no país); e em 1995 da APROVALE (Associação de Produtores de Vinho do Vale dos Vinhedos), fundada com o objetivo de promover o desenvolvimento sustentável do Vale dos Vinhedos através do enoturismo.

Observa-se que durante vários anos os produtores da região se organizaram a partir de cooperativas, e o modus operandi vigente incluía a entrega da colheita, que era processada e transformada em vinho. As Cooperativas Aurora e Garibaldi surgiram em 1931 e a história da região se funde à história de suas iniciativas. Por exemplo, a Cooperativa Garibaldi surgiu como uma solução para dar destino à uva produzida, foi a primeira a lançar vinhos varietais (vinhos produzidos a partir de uma única uva sem cortes com outras variedades) no Brasil com a marca histórica Granja União e contribuiu para o avanço das pesquisas e de uma vitivinicultura mais elaborada. Esta Cooperativa realizou a sua primeira exportação em 1948, em 1990 criou um complexo turístico e desde os anos 2000 trabalha para mostrar é capaz de produzir não apenas o vinho de garrafão, mas tem alta tecnologia e capacidade para produção de vinhos finos (Vinícola Garibaldi, 2017).

Na década de 1980, com o enfraquecimento de algumas cooperativas, um grupo de viticultores desligou-se e buscou a profissionalização de sua produção, direcionando seus filhos para cursos de enologia e viticultura, criando muitas das vinícolas com administração familiar que existem até hoje(Dallanhol \& Tonini, 2012). Com a busca pela profissionalização, o desenvolvimento do enoturismo tornou-se uma estratégia de divulgação e complementação de renda por estes espaços.

É imprescindível mencionar a importância da implantação e o desenvolvimento do Projeto Economia da Experiência em sete municípios da região: Bento 
Gonçalves, Caxias do Sul, Cotiporã, Garibaldi, Nova Prata, Veranópolis e Vila Flores. Este projeto foi desenvolvidoem uma parceria entre o Ministério do Turismo, o Serviço Brasileiro de Apoio às Micro e Pequenas Empresas - SEBRAE Nacional, o Sindicato de Hotéis, Restaurantes, Bares e Similares - SHRBS da Região da Uva e do Vinho e o Instituto Marca Brasil em 2006. 0 objetivo foi formatar produtos turísticos capazes de garantir a interação do turista com a natureza e a cultura local, tornando-o personagem do contexto visitado, desenvolvendo vários produtos associados ao universo do vinho (Brasil, 2015).

Deve-se observar que, além do vinho, outros elementos da Serra Gaúcha também são responsáveis pela atração de turistas. A região é, na verdade,um importante destino turístico brasileiro, um dos principais expoentes da oferta turística do Rio Grande do Sul, atendendo sobretudo à demanda doméstica de viajantes. A Serra oferece sobretudo atrativos associados ao frio e à natureza, tais como eventos culturais, gastronomia (com destaque, além do enoturismo, para produtos como chocolate, café colonial, churrasco e comida italiana e alemã), ambientes aconchegantes, trilhas, cachoeiras e atividades de aventura, oferecidos por municípios como como Nova Petrópolis, Gramado, Canela, Flores da Cunha, Nova Pádua e Bento Gonçalves. Contudo, apesar do destaque, a visitação enoturística das vinícolas da Serra Gaúcha ainda não foi sistematicamente descrita na literatura acadêmica. Desta forma, a seção a seguir busca preencher essa lacuna.

\section{Visitação de vinícolas na Serra Gaúcha}

O estudo das práticas de visitação nas vinícolas da Serra Gaúcha foi realizado a partir de entrevistas semiestruturadas de caráter qualitativo com os gestores de estabelecimentos. As vinícolas foram selecionadas a partir de uma tentativa de realização de pesquisa censitáriadentre aquelas que fazem parte das associações APROVALE, APROBELO, ASPROVINHO, CPEG/AVIGA, as quais representam a coletividade de vinícolas dos municípios de Bento Gonçalves, Monte Belo do Sul, Garibaldi (Vale dos Vinhedos) e Pinto Bandeira no estado do Rio Grande do Sul.

Contudo, a coleta de dados foi limitada pela colaboração dos gestores de cada estabelecimento, bem como a disponibilidade de tempo e recursos para a realização da pesquisa. Foram pesquisadas 17 vinícolas, representando20\% do total de estabelecimentos identificados. Dentre estas, três não realizavam atendimento ao turista, definindo a amostra final em 14 vinícolas. 0 Quadro 2 apresenta os estabelecimentos que integraram a amostra:

Quadro 2 - Vinícolas pesquisadas e respectivas regiões produtoras.

\begin{tabular}{|l|l|l|} 
& \multicolumn{1}{|c|}{ Vinícola } & \multicolumn{1}{c|}{ Região produtora } \\
\hline $\mathbf{1}$ & Don Laurindo & Vale dos Vinhedos \\
\hline $\mathbf{2}$ & Lídio Carraro & Vale dos Vinhedos \\
\hline $\mathbf{3}$ & Michele Carraro & Vale dos Vinhedos \\
\hline $\mathbf{4}$ & Miolo & Vale dos Vinhedos \\
\hline $\mathbf{5}$ & Peculiare & Vale dos Vinhedos \\
\hline $\mathbf{6}$ & Pizzato & Vale dos Vinhedos \\
\hline
\end{tabular}

(continua...) 
Quadro 2 - Continuação

\begin{tabular}{|l|l|l|}
\hline & \multicolumn{1}{|c|}{ Vinícola } & \multicolumn{2}{c|}{ Região produtora } \\
\hline $\mathbf{7}$ & Cooperativa Aurora & Pinto Bandeira \\
\hline $\mathbf{8}$ & Valmarino & Pinto Bandeira \\
\hline $\mathbf{9}$ & Faé & Monte Belo do Sul \\
\hline $\mathbf{1 0}$ & Fantin & Monte Belo do Sul \\
\hline $\mathbf{1 1}$ & Cooperativa Garibaldi & Garibaldi \\
\hline $\mathbf{1 2}$ & Vaccaro & Garibaldi \\
\hline $\mathbf{1 3}$ & Battistello & Garibaldi \\
\hline $\mathbf{1 4}$ & Milantino & Garibaldi \\
\hline
\end{tabular}

Fonte - elaboração própria.

Apesar das restrições, a amostra se revelou satisfatória para a descrição do enoturismo na região em virtude do considerável grau de saturação das informações obtidas. As entrevistas foram realizadas no período do mês de maio de 2015, abordando o gestor de cada estabelecimento pessoalmente por períodos que variaram entre 15 a 60 minutos. As falas foram transcritas e suas informações foram analisadas a partir de quadros sínteses, apresentados na sequência deste artigo.

Deve-se mencionar que, dentre os estabelecimentos pesquisados, encontram-se exemplos de diferentes portes e em distintos estágios de desenvolvimento turístico. 0 Quadro 3 apresenta os dados gerais de cada vinícola pesquisada:

Quadro 3 - Quadro produtivo das vinícolas pesquisadas.

\begin{tabular}{|c|c|c|c|c|c|}
\hline & Vinícola & $\begin{array}{l}\text { Hectares de } \\
\text { vinhedos } \\
\text { próprios }\end{array}$ & $\begin{array}{c}\text { Qtde de } \\
\text { litros/ano* }\end{array}$ & $\begin{array}{c}\text { Qtde de } \\
\text { garrafas / } \\
\text { ano* }\end{array}$ & $\begin{array}{c}\text { Número } \\
\text { de Funcionários* }\end{array}$ \\
\hline 1 & $\begin{array}{l}\text { Cooperativa } \\
\text { Aurora }\end{array}$ & $\begin{array}{l}\text { Não } \\
\text { informado }\end{array}$ & 38.000 .000 & 50.540 .000 & $\begin{array}{l}1.100 \text { famílias } \\
\text { cooperadas }\end{array}$ \\
\hline 2 & Miolo & 1000 & 12.000 .000 & 15.960 .000 & Não informado \\
\hline 3 & $\begin{array}{l}\text { Coop. } \\
\text { Garibaldi }\end{array}$ & 850 & $\begin{array}{l}\text { Não } \\
\text { informado }\end{array}$ & $\begin{array}{l}\text { Não } \\
\text { informado }\end{array}$ & 370 \\
\hline 4 & Vaccaro & 30 & 300.000 & 400.000 & 6 \\
\hline 5 & Lídio Carraro & 43 & 225.000 & 300.000 & 33 \\
\hline 6 & Valmarino & 16 & 200.000 & 266.000 & 11 \\
\hline 7 & Pizzato & 45 & 173.000 & 230.000 & 40 \\
\hline 8 & Don Laurindo & 15 & 90.000 & 120.000 & 8 \\
\hline 9 & Milantino & $\begin{array}{l}\text { Não } \\
\text { informado }\end{array}$ & 60.000 & 80.000 & A própria família \\
\hline 10 & Peculiare & 6 & 15.000 & 20.000 & 4 \\
\hline 11 & Faé & 0 & 6.000 & 8.000 & 3 \\
\hline 12 & Fantín & $\begin{array}{l}\text { Não } \\
\text { informado }\end{array}$ & 1.500 & 2.000 & 3 \\
\hline 13 & Battistello & 11 & $\begin{array}{l}\text { Não } \\
\text { informado }\end{array}$ & $\begin{array}{l}\text { Não } \\
\text { informado }\end{array}$ & 4 \\
\hline 14 & $\begin{array}{l}\text { Michelle } \\
\text { Carraro }\end{array}$ & $\begin{array}{l}\text { Não } \\
\text { informado }\end{array}$ & $\begin{array}{l}\text { Não } \\
\text { informado }\end{array}$ & $\begin{array}{l}\text { Não } \\
\text { informado }\end{array}$ & A própria família \\
\hline
\end{tabular}

Fonte - elaboração própria. 
As vinícolas Cooperativa Aurora (Pinto Bandeira), Miolo (Vale dos Vinhedos) e Cooperativa Garibaldi (Garibaldi)são as maiores produtoras e podem ser consideradas de grande porte, com média de 25.000.000 de litros produzidos anualmente. As vinícolas Vaccaro, Lídio Carraro, Valmarino, Pizzato e Don Laurindo são consideradas de médio porte, produzindo cerca de 197.600 litros/ano e Peculiare, Faé, Fantín, Battistello e Michelle Carraro de pequeno porte, produzindo em média 13.750 litros/ano, sendo que a Michelle Carraro atua em escala quase artesanal. Deve-se mencionar que a Cooperativa Aurora, a vinícola Miolo e a Cooperativa Garibaldi são também as que possuem maior abrangência de distribuição de seus produtos, sendo conhecidas em todo o Brasil. A Cooperativa Aurora, inclusive, exporta seus produtos para vários países e é certificada pela ISO 9001 e ISO 14000 (Vinícola Aurora, 2017).

Todas as vinícolas trabalham com vinhos finos, sendo as uvas mais comuns: Chardonnay, Merlot, Moscatel e Riesling Itálico, e quase todas as vinícolas trabalham com espumantes, especialmente os de característica Brut.

\section{Histórico da visitação}

Como já observado, as vinícolas estudadas se encontram em diferentes estágios de desenvolvimento turístico. 0 Quadro 4 indica o ano de fundação das vinícolas e o ano de início da atividade turística:

Quadro 4 - Ano de fundação e de início da atividade enoturística das vinícolas.

\begin{tabular}{|l|l|l|l|l|}
\hline & \multicolumn{1}{|c|}{ Vinícola } & \multicolumn{1}{|c|}{ Região } & Ano de fundação & $\begin{array}{c}\text { Ano de início da ativi- } \\
\text { dade enoturística }\end{array}$ \\
\hline $\mathbf{1}$ & Coop. Aurora & Pinto Bandeira & 1931 & 1967 \\
\hline $\mathbf{2}$ & Coop. Garibaldi & Garibaldi & 1931 & 1990 \\
\hline $\mathbf{3}$ & Vaccaro & Garibaldi & 1955 & 2001 \\
\hline $\mathbf{4}$ & Michelle Carraro & Vale dos Vinhedos & 1985 & 2003 \\
\hline $\mathbf{5}$ & Faé & Monte Belo do Sul & 1988 & 2014 \\
\hline $\mathbf{6}$ & Miolo & Vale dos Vinhedos & 1989 & 1992 \\
\hline $\mathbf{7}$ & Milantino & Garibaldi & 1990 & 2015 \\
\hline $\mathbf{8}$ & Don Laurindo & Vale dos Vinhedos & 1995 & 1995 \\
\hline $\mathbf{9}$ & Valmarino & Pinto Bandeira & 1997 & 2001 \\
\hline $\mathbf{1 0}$ & Pizzato & Vale dos Vinhedos & 1998 & 2000 \\
\hline $\mathbf{1 1}$ & Fantín & Monte Belo do Sul & 2001 & 2001 \\
\hline $\mathbf{1 2}$ & Peculiare & Vale dos Vinhedos & 2002 & 2003 \\
\hline $\mathbf{1 3}$ & Lídio Carraro & Vale dos Vinhedos & 2004 & 2004 \\
\hline $\mathbf{1 4}$ & Battistello & Garibaldi & 2005 & 2005 \\
\hline & & & \\
\hline
\end{tabular}

Fonte - elaboração própria.

As Cooperativas Aurora e Garibaldi são as que estão há mais tempo em funcionamento, tendo sido inauguradas na década de 1930. Outra vinícola de grande porte, a Miolo, iniciou suas atividades na década de 1980, assim como a Michelle Carraro e a Faé. Como observam Dallanhol e Tonini (2012), a década de 1980 
marcou a profissionalização da produção do vinho na região, e 11 das 14 vinícolas estudadas foram fundadas a partir deste período.

As três vinícolas de maior porte - Cooperativa Aurora, Cooperativa Garibaldi e Miolo - são as precursoras no atendimento a turistas. As entrevistas revelaram que o enoturismo na região não se deu de uma forma marcadamente planejada e fomentada por ações de marketing, sendo estes tipos de ações realizadas de forma mais reativa. Em alguns casos, como na vinícola Miolo, os primeiros serviços de recepção de turistas foram criados pelo proprietário com inspiração nos serviços ofertados em vinícolas do exterior. Esses pioneiros inspiraram as demais vinícolas da região, descrevendo um típico processo de transferência e transbordamento de tecnologia. $\mathrm{O}$ apoio do poder público e de entidades como o SEBRAE também ganhou força somente após o fluxo turístico já ter atingido certa expressividade. Observa-se que muitas das vinícolas mais jovens começaram as atividades de enoturismo de forma concomitante à sua fundação, justamente no rastro dos demais exemplos bem sucedidos da Serra Gaúcha e pelo entendimento de que as visitações fortalecem a marca e divulgam os produtos para novos consumidores.

Deve-se mencionar também a importância de eventos como a Festa Nacional do Vinho (Fenavinho) que teve início em 1967 em Bento Gonçalves (que marcou o início das atividades enoturísticas da Cooperativa Aurora) e a Festa do Espumante Brasileiro (Fenachamp) que começou em Garibaldi em 1981. Iniciativas como o já mencionado projeto Economia da Experiência, além da Rota dos Espumantes $^{2}$, a Estrada do Sabor ${ }^{3}$ (ambas em Garibaldi) e Caminhos de Pedra ${ }^{4}$ (Bento Gonçalves) também são elementos importantes para a atração de turistas para as vinícolas.

\section{Quantidade e perfil dos visitantes}

Em 2013, o Vale dos Vinhedos recebeu 283 mil turistas, sendo 60 mil só no primeiro trimestre do ano (Vale dos Vinhedos, 2017), mas a maioria das vinícolas estudadas, apesar de reconhecerem a importância do turismo para o funcionamento da vinícola, declararam não possuir nenhum controle formal do fluxo de visitantes, o que impede a indicação de qualquer número. As informações coletadas podem ser visualizadas no Quadro 5.

2. Rota dos Espumantes: É composta por 20 vinícolas, dentre elas Battistello, Cooperativa Garibaldi, Don Laurindo, Milantino e Vaccaro.

3. Estrada do Sabor: Envolve famílias que possuem como principal atividade a agricultura e a agroindústria, recebendo os turistas em suas propriedades. Atualmente integram o projeto: Família Bettú: (degustação e venda de vinhos especiais), Família Jorge Mariani (agricultura ecológica, com degustação e venda de vinhos, pães, queijos e salames), Família Odete Bettú Lazzari (refeições), Família Olir Brugalli (produção e comercialização de pães, queijos, copas, salames, vinhos e sucos), Família Vaccaro (refeições, degustações de vinho, visita à vinícola).

4. Caminhos de Pedra: É composto sete quilômetros que passa por 28 construções em pedra e madeira, formando um cenário que remete à região Norte da Itália. São moinhos, casas de massas, de teares, de erva-mate e de ovelhas, além de cantinas e capelas. 
Quadro 5 - Quantidade de visitantes.

\begin{tabular}{|l|l|l|}
\hline & \multicolumn{1}{|c|}{ Vinícola } & \multicolumn{2}{c|}{ Número de Visitantes/ano } \\
\hline $\mathbf{1}$ & Número de Visitantes/ano & 200.000 \\
\hline $\mathbf{2}$ & Coop. Aurora & 150.000 \\
\hline $\mathbf{3}$ & Coop. Garibaldi & 75.000 \\
\hline $\mathbf{4}$ & Pizzato & 6.000 \\
\hline $\mathbf{5}$ & Vaccaro & 4.000 \\
\hline $\mathbf{6}$ & Valmarino & 3.000 \\
\hline $\mathbf{7}$ & Battistello & Não informado \\
\hline $\mathbf{8}$ & Don Laurindo & Não informado \\
\hline $\mathbf{9}$ & Lídio Carraro & Não informado \\
\hline $\mathbf{1 0}$ & Peculiare & Não informado \\
\hline $\mathbf{1 1}$ & Faé & Muito inicial o recebimento de turistas \\
\hline $\mathbf{1 2}$ & Fantín & Muito inicial o recebimento de turistas \\
\hline $\mathbf{1 3}$ & Milantino & Muito inicial o recebimento de turistas \\
\hline $\mathbf{1 4}$ & Michelle Carraro & Não possuem registros formais \\
\hline & & Fonte - elaboração própria. \\
\hline
\end{tabular}

Como já esperado, são as vinícolas de maior porte - e também as mais conhecidas no país- que recebem o maior número de visitantes. Os principais mercados são o Rio Grande do Sul, Santa Catarina, Paraná, São Paulo e Minas Gerais. Contudo, a demanda não se restringe a esses estados, já que as vinícolas recebem turistas de todo o Brasil e também de outros países. Na demanda internacional destacam-se os turistas argentinos. 0 fluxo de turistas em geral se concentra principalmente nos meses de dezembro a fevereiro, época em que a colheita da uva coincide com férias escolares, e em julho, mês de férias escolares e temporada de inverno.

Dentre os turistas que residem mais longe, uma parcela considerável não tem a região das vinícolas como principal destino de suas viagens. São muito frequentes os turistas que se dirigem a Gramado(RS) ou Canela(RS), utilizando estas cidades como ponto de apoio para a realização de excursões de um dia para visitar as vinícolas. Nestes casos, muitas vezes a visitação é organizada por meio de agências de turismo receptivo de Gramado ou Canela.

Uma grande parcela dos turistas das grandes vinícolas viaja em ônibus de excursão, incluindo aqueles que partem de Gramado ou Canela, e também aqueles que fazem roteiros rodoviários por diferentes regiões. Nas vinícolas menores, quase todos os turistas viajam em automóveis particulares. Essa característica se reflete no maior poder aquisitivo e maior grau de interesse pelo vinho dos turistas das vinícolas menores.

Grande parte da demanda é composta por casais sem filhos, mas a presença de famílias com crianças também é frequente. Para estes casos as vinícolas geralmente têm poucas atrações e serviços especializados, de forma que as crianças costumam se entreter com os elementos diferenciados da paisagem e degustar suco de uva.

Além dos turistas motivados essencialmente pelo lazer, existem também os grupos de estudo, como os de escolas e universidades. Dentre os grupos de uni- 
versidades, destacam-se aqueles dos cursos de Engenharia Ambiental, Engenharia Química, Gastronomia, Turismo, Administração e Enologia.

Os turistas em geral apresentam variados níveis de conhecimento prévio sobre vinhos. Se considerarmos a tipologia proposta por Charters e Ali-Knight (2002), a região recebe desde pessoas que provam vinho pela primeira vez na vida (novatos do vinho) até grandes experts (conhecedores de vinhos). Contudo, a maioria dos visitantes são pessoas que bebem vinho cotidianamente, apresentando alguma experiência com o produto, mas sem trazer conhecimentos técnicos profundos, o que caracterizaria uma predominância da categoria 'interessados em vinho'. Se considerada a tipologia proposta por Johnson (1998), que separa os enoturistas entre 'especialistas' e 'genéricos', verifica-se uma prevalência da segunda categoria, embora a primeira também seja atendida.

Identificou-se que cada pessoa costuma visitar quatro ou cinco vinícolas por dia, o que leva muitos estabelecimentos a diversificar sua oferta de atividades ou até mesmo selecionar as informações que serão repassadas durante a visita, de forma a não repetir dados e cansar os visitantes.

\section{Estrutura e organização receptiva}

As diversas vinícolas da região que trabalham diretamente com turistas apresentam dimensões significativamente heterogêneas. As maiores vinícolas - e também as com maior tradição neste atendimento -a Cooperativa Aurora e a Miolo, apresentam estruturas relativamente grandes para recepção, contando com equipes de atendimento com algumas dezenas de funcionários, como pode ser observado no Quadro 3. Esses estabelecimentos geralmente têm com boa acessibilidade e capacidade para receber alguns ônibus de turistas ao mesmo tempo e em consequência são mais procuradas por grupos de agências de viagens e excursões. Contudo, grupos familiares e pequenos grupos de amigos também visitam esses estabelecimentos.

Já as vinícolas menores geralmente apresentam um padrão menos massificado, atendendo principalmente grupos familiares e de amigos. Há um entendimento entre os representantes entrevistados destas vinícolas que as mesmas são procuradas por aqueles que já conhecem os estabelecimentos maiores e buscam uma experiência diferente, mais 'autêntica' e menos turística. 0 acesso em alguns casos é mais difícil em razão da distância da cidade e da falta de asfaltamento das estradas e a estrutura receptiva é geralmente mais informal. Há casos, inclusive, em que o atendimento aos turistas é feito na casa do proprietário do estabelecimento, como acontece nas vinícolas Faé e Fantín.

\section{Roteiros de visitação}

Os programas de visitação das vinícolas apresentam alguns padrões recorrentes, o que permitiu a definição de quatro categorias, apresentadas no Quadro 6. 
Quadro 6 - Categorias dos programas de visitação.

\begin{tabular}{|c|c|c|}
\hline $\begin{array}{l}\text { Categorias dos pro- } \\
\text { gramas de visitação }\end{array}$ & Principais características & Vinícolas \\
\hline Básico & $\begin{array}{l}\text { Oferecem informações sobre a } \\
\text { produção e degustação de vinhos. }\end{array}$ & $\begin{array}{l}\text { Battistelo, Michele Carraro, } \\
\text { Milantino, }\end{array}$ \\
\hline Regular & $\begin{array}{l}\text { Além das informações e da } \\
\text { degustação, oferecem a visitação de } \\
\text { determinadas áreas da vinícola. }\end{array}$ & $\begin{array}{l}\text { Peculiare, Faé, Valmarino, } \\
\text { Lídio Carraro, Don Laurindo, } \\
\text { Fantín }\end{array}$ \\
\hline Diferenciado & $\begin{array}{l}\text { Oferecem informações sobre } \\
\text { a produção e degustação de } \\
\text { vinhos e elementos exclusivos } \\
\text { como degustações diferenciadas, } \\
\text { colheita de uva e outras atividades. } \\
\text { Regularmente ofertados pelas } \\
\text { vinícolas com maior estrutura } \\
\text { receptiva. }\end{array}$ & Pizzato, Vaccaro \\
\hline Especial & $\begin{array}{l}\text { Oferecem serviços especiais sob } \\
\text { demanda de grupos específicos. Os } \\
\text { integrantes dessa categoria podem } \\
\text { pertencer a qualquer uma das três } \\
\text { categorias anteriores. }\end{array}$ & $\begin{array}{l}\text { Miolo, Cooperativa Aurora, } \\
\text { Cooperativa Garibaldi }\end{array}$ \\
\hline
\end{tabular}

Fonte - elaboração própria.

O programa básico, que geralmente é o padrão em vinícolas pequenas, é aquele que inclui somente o oferecimento de informações e a degustação de vinhos. 0 atendimento é bastante personalizado, sendo que as informações fornecidas geralmente variam de acordo com o cliente, podendo tratar de temas relacionados à história, produção vitivinícola, tradições locais, características específicas da vinícola, e também de acordo com as vinícolas já visitadas, tanto em razão do nível de conhecimento adquirido quanto devido ao cansaço dos turistas. A degustação geralmente inclui de um a três vinhos de diferentes tipos. Para pessoas que não bebem vinho, incluindo as crianças, a maioria das vinícolas oferecem suco de uva.

O programa regular, além das informações e da degustação, inclui a visitação de determinadas áreas da vinícola, definidas por cada estabelecimento. Contudo, alguns dos pontos comuns são os vinhedos, as antigas e as atuais instalações de produção de vinho e as áreas de armazenagem do produto. Quando ocorre a visitação à plantação, geralmente são apresentadas informações sobre as videiras, o solo e o clima. Nas antigas instalações produtivas usualmente são apresentados equipamentos tradicionais, como prensas, tonéis, barricas de carvalho, garrafas e outros. As instalações atuais de produção permitem que o turista visualize os equipamentos correntemente utilizados, a movimentação de trabalhadores e insumos e as análises químicas e enológicas do vinho em elaboração. Estes programas regulares são majoritariamente ofertados pelas vinícolas com maior estrutura. 0 roteiro de visitação tradicional geralmente é pré-estabelecido, não prevendo a possibilidade de alterações para satisfazer demandas específicas do grupo.

Os programas básicos ou regulares nas vinícolas maiores custam em torno de $R \$ 15,00$ por pessoa. 0 valor cobrado pela visitação geralmente pode ser utilizado parcial ou integralmente como crédito revertido em compras na loja da 
vinícola. Nas vinícolas menores e com programas de visitação mais flexíveis o serviço é muitas vezes gratuito. Nestes casos, como o fluxo de visitantes é mais selecionado, a maioria dos turistas adquire produtos na loja da propriedade, de forma que a receita de vendas substitui a do ingresso do roteiro.

Os programas diferenciados usualmente incluem alguns elementos exclusivos que não fazem parte do programa regular. Em muitos casos o diferencial está na visitação de um espaço específico que não é usualmente visitado naquela vinícola em particular. Há também programas que oferecem degustações diferenciadas que incluem a prova de um maior número de vinhos. Nesses casos a degustação geralmente é feita em ambientes mais reservados e estruturados. Existe ainda o programa sazonal da colheita da uva, no qual os turistas participam ativamente do trabalho agrícola, obtendo maior contato e informação sobre o processo. Estes programas diferenciados são regularmente ofertados pelas vinícolas com maior estrutura receptiva.

Por fim, os roteiros especiais são organizados sob demanda, incluindo a visitação de pontos fechados a grupos comuns ou informações detalhadas sobre determinado aspectode interesse específico. Neste último caso um enólogo capacitado é designado para explicar minuciosamente o processo produtivo. E existem também os casos de grupos com interesse em outros aspectos do negócio vinícola, como administração, marketing, recursos humanos e outros.

O Quadro 7 identifica os principais serviços oferecidos por estas vinícolas, o que permite uma melhor compreensão do que pode compor uma visita:

Quadro 7 - Serviços oferecidos pelas vinícolas estudadas.

\begin{tabular}{|c|c|c|c|c|c|c|c|c|}
\hline Vinícola & $\begin{array}{l}\text { De- } \\
\text { gusta- } \\
\text { ção }\end{array}$ & $\begin{array}{l}\text { Visita } \\
\text { pro- } \\
\text { dução }\end{array}$ & $\begin{array}{l}\text { Visita } \\
\text { vinhe- } \\
\text { do }\end{array}$ & $\begin{array}{l}\text { Co- } \\
\text { lhei-ta }\end{array}$ & $\begin{array}{l}\text { Ali- } \\
\text { men- } \\
\text { tação }\end{array}$ & $\begin{array}{l}\text { Even- } \\
\text { to }\end{array}$ & $\begin{array}{l}\text { Cur- } \\
\text { sos }\end{array}$ & $\begin{array}{l}\text { Loja/ } \\
\text { Venda } \\
\text { pro- } \\
\text { dutos }\end{array}$ \\
\hline \multicolumn{9}{|c|}{ Região Vale dos Vinhedos } \\
\hline \multicolumn{9}{|l|}{ Don Laurindo } \\
\hline Lídio Carraro & & & & & $*$ & & & \\
\hline \multicolumn{9}{|c|}{ Michele Carraro } \\
\hline \multicolumn{9}{|l|}{ Miolo } \\
\hline \multicolumn{9}{|l|}{ Peculiare } \\
\hline Pizzato & & & & & $*$ & & & \\
\hline \multicolumn{9}{|c|}{ Região Pinto Bandeira } \\
\hline \multicolumn{9}{|l|}{ C. Aurora } \\
\hline \multicolumn{9}{|l|}{ Valmarino } \\
\hline \multicolumn{9}{|c|}{ Região Monte Belo do Sul } \\
\hline \multicolumn{9}{|l|}{ Faé } \\
\hline \multicolumn{9}{|l|}{ Fantín } \\
\hline \multicolumn{9}{|c|}{ Região Garibaldi } \\
\hline \multicolumn{9}{|l|}{ Battistello } \\
\hline \multicolumn{9}{|l|}{ C. Garibaldi } \\
\hline \multicolumn{9}{|l|}{ Milantino } \\
\hline Vaccaro & & & & & & & & \\
\hline
\end{tabular}

Fonte - elaboração própria. 
O quadro 7 evidencia o esforço para a oferta de diferentes atividades, de forma a aumentar não apenas a atratividade do empreendimento, mas também a satisfazer diferentes perfis de visitantes. Por exemplo, verifica-se que seis vinícolas contam com serviço de alimentação, com restaurantes voltados para comidas típicas da colonização italiana, como massas, queijos e embutidos. Um serviço diferenciado é ofertado pela vinícola Vaccaro: o turista monta uma cesta com produtos coloniais e faz sua refeição em qualquer espaço da propriedade, incluindo os bucólicos parreirais. A vinícola Miolo, por sua vez, recebe food trucknos finais de semana. Duas vinícolas, Lídio Carraro e Pizatto, oferecem serviços de alimentação para grupos, mas em restaurantes da região que fornecem refeições em suas dependências com cardápio harmonizado com vinhos de cada propriedade.

Quatro vinícolas dispõem de espaços para a realização de eventos, que costumam ser alugados não apenas para a realização de festas, aniversários e casamentos, mas também para jantares de associações, clubes e confrarias ligadas ao vinho. Serviços de coquetel e até de buffet são prestados por algumas vinícolas fora de seus espaços próprios, como as vinícolas Pizzato e Lídio Carraro. Nestes casos, a vinícola serve o almoço ou jantar em hotéis e outros espaços durante eventos sociais e comerciais. A realização de degustações em feiras e eventos comerciais também é uma estratégia de divulgação usual de produtos.

Três vinícolas oferecem cursos de diversas modalidades e especialidades. Em termos de duração, os cursos variam de poucas horas até um ano e meio. Em conteúdo, vão desde uma introdução à enologia para leigos até programas completos, incluindo cursos específicos sobre questões técnicas da produção vinícola. Os cursos introdutórios normalmente incluem informações sobre a história, o processo produtivo e a degustação de diferentes tipos de vinhos. 0 programa mais longo é oferecido pela vinícola Miolo: o visitante participa de todo o processo produtivo, incluindo a colheita da uva, a prensa, o processo nos tanques, o engarrafamento e a rotulagem. Esse programa inclui três momentos na vinícola, de forma que os inscritos precisam viajar repetidamente para o destino. Ao final do curso, o turista-aluno leva para casa dez caixas de vinhos com seu nome no rótulo.

Todas as vinícolas têm produtos à venda, reforçando o que é exposto porDallanhol e Tonini (2012), Gimenes (2012),Hall, Sharples, et al. (2000)e Mitchell e Hall (2003) em relação à complementação de renda para a vinícola. Algumas ofertam apenas o próprio vinho, mas a maioria possui lojas bem estruturadas com uma vasta gama de produtos. Pode-se identificar seis categorias de produtos vendidos. 0 primeiro conjunto naturalmente é formado pelos diversos vinhos produzidos na vinícola. 0 segundo grupo inclui os produtos diretamente associados ao consumo do vinho, tais como saca-rolhas, rolhas vedantes, taças, baldes de vinho, dosadores e estojos para garrafas e taças. Em terceiro lugar estão os produtos alimentícios, como sucos, licores, grapa (destilado da uva),vinagres, geleias, doces em compota, biscoitos e queijos.

Um quarto conjunto é composto pelos produtos que guardam e disponibilizam conhecimento sobre o vinho e aspectos relacionados, como livros e DVDs. Em quinto lugar pode-se identificar o comércio de diversos tipos de artesanatos e souvenires com símbolos que remetem ao vinho ou que levam a marca da vinícola. Neste caso, tem-se objetos como porta-retratos, roupas, chaveiros, calendários, jogos, brinquedos infantis, cosméticos e outros. Neste conjunto estão 
inclusive alguns objetos que fazem brincadeiras ou piadas populares com o tema do vinho como, por exemplo, os produtos que trazem impresso, em fonte característica, o trocadilho "Tommy Vinho", em referência à marca norte-americana de moda Tommy Hilfiger.

O sexto conjunto é formado pelos objetos que não mantém nenhuma relação direta com o negócio principal da vinícola. Neste conjunto estão os produtos com símbolos que remetem a outros elementos locais, como cuias de chimarrão, cartões postais e souvenires com o nome da cidade ou do estado. Enquadram-se nesta categoria também os souvenires de produção local que não trazem nenhum símbolo que remeta a essa origem. Por fim, estão incluídos nesse conjunto alguns objetos básicos de necessidade dos turistas, como garrafas de água, pilhas, cartões de memória digital e outros.

É interessante notar que os produtos associados ao vinho e que carregam a marca da vinícola são vistos pelos empresários não apenas como uma fonte de receita, mas também como uma forma de fortalecer suas marcas. Além disso, é importante destacar que parte da produção de itens disponibilizados à venda é realizada pelos familiares dos trabalhadores e proprietários das vinícolas, de forma que a retenção de renda no núcleo familiar seja ampliada.

A maioria dos visitantes das vinícolas adquire itens nas lojas dos estabelecimentos. 0 percentual de turistas que compram ao menos um item chega a $90 \%$ em algumas vinícolas. 0 valor total da compra claramente varia de acordo com o tipo de roteiro de visitação feito, de forma que quanto mais diferenciado ou especial o roteiro, maior tende a ser o gasto. Na Cooperativa Garibaldi, por exemplo, o ticket médio dos turistas que fazem o roteiro diferenciado gira em torno de $\mathrm{R} \$$ 50,00 .

\section{Comunicação e promoção}

A comunicação das vinícolas com o mercado consumidor potencial é feita de diversas formas. A publicidade em mídias tradicionais fica restrita essencialmente às grandes vinícolas, como a Cooperativa Aurora, a Cooperativa Garibaldi e a vinícola Miolo. É bastante disseminada a participação em feiras do setor e a formação de parcerias com agências de turismo, hotéis, restaurantes e outros estabelecimentos turísticos. Os veículos de comunicação on-line também têm sido bastante utilizados, incluindo ferramentas como Facebook, Twitter e os diversos portais de viagens. Todas as vinícolas possuem páginas eletrônicas próprias, com exceção das vinícolas Faé e Fantín, que são divulgadas pela APROBELO. Das doze vinícolas que possuem página eletrônica própria, apenas seis divulgam suas atividades enoturísticas, sendo que a Miolo é a que disponibiliza o maior número de informações, indicando não apenas os dias e horários, mas também valores e as atividades que podem ser realizadas.

As vinícolas também contam com grande apoio de comunicação dos canais de notícias e reportagens. Jornais e revistas com frequência veiculam informações espontaneamente sobre os mais diversos aspectos relacionados às vinícolas, incluindo os vinhos, os processos produtivos, os serviços de recepção de turistas, 
os cursos, etc. Um canal de comunicação de divulgação que vem ganhando grande importância nos últimos anos são osblogs especializados em vinhos e gastronomia, além dos guias anuais que apresentam os vinhos premiados.

Estas premiações são importantes para a visibilidade da vinícola e de seus vinhos e as distinções são destacadas nas páginas eletrônicas das vinícolas Cooperativa Aurora, Miolo, Cooperativa Garibaldi, Vaccaro, Lídio Carraro, Pizzato e Battistello. Segundo os entrevistados, sempre que um vinho é premiado sua demanda cresce substancialmente e, como consequência, cresce também a visitação à vinícola. Esse tipo de premiação também é utilizado como argumento de valorização do vinho para turistas durante a visitação.

\section{Considerações finaIs}

Apesar da tradição na produção vitivinícola, o surgimento e desenvolvimento do enoturismo no Rio Grande do Sul é recente. Essa curta história revela uma rápida trajetória ascendente, tanto em termos de quantidade de visitantes quanto na qualidade dos serviços ofertados. Este sucesso se dá não apenas por conta da iniciativa empreendedora dos produtores, mas também pela qualidade do vinho produzido e pela sua associação a outros atrativos turísticos da região.

O corpus pesquisado permite observar que a relação entre a produção vinícola e o turismo na Serra Gaúcha hoje se configura como simbiótica. Reproduzindo o que é observado na literatura, verifica-se que, por um lado, o turismo na região depende intimamente do vinho, mas também é um elemento fundamental para o crescimento desta indústria, contribuindo para a divulgação e fortalecimento das marcas das vinícolas e aumentando o escoamento da produção a partir do relacionamento direto com o consumidor.

A partir dos dados levantados, observou-se que o enoturismo na região em questão vem se desenvolvendo a partir de um conjunto heterogêneo de propriedades, tanto no que diz respeito às dimensões e características de produção, como em termos da oferta de atividades de visitação. É possível, neste sentido, encontrar produtos destinados a diferentes perfis de visitantes, considerando diferentes paladares, perfis de consumo, padrões de sofisticação e até mesmo diferentes interesses e conhecimentos prévios relacionados ao universo vitivinícola.

As grandes vinícolas muitas vezes são procuradas por serem marcas famosas e já consumidas, além da divulgação propiciada pelo investimento em marketing e acordos comerciais com agências. As vinícolas pequenas, por sua vez, apesar da pouca divulgação, são procuradas muitas vezes por visitantes que já estiveram na região e/ou por aqueles que desejam conhecer e degustar uma forma de produção mais artesanal. A visitação de vinícolas menores também proporciona experiências e conhecimentos mais exclusivos, que diferenciam o visitante da massa de turistas. Isto pode render elementos que favorecem a autoafirmação e o destaque social dos visitantes dessas vinícolas que estão fora dos circuitos tradicionais.

Mesmo considerando esta heterogeneidade, as entrevistas permitem identificar que o enoturismo foi assumido como uma atividade relevante, seja pelas funções já mencionadas de comercialização da produção vinícola e divulgação da marca, mas também pela possibilidade de complementação de renda a partir da 
comercialização de outros produtos associados à marca ou à região. Os dados levantados, desta forma, confirmam os benefícios socioeconômicos do enoturismo apontados por Hall, Johnson, et al. (2000), Gimenes (2012). Hall, Sharples, et al. (2000), Dallanhol e Tonini (2012) e Mitchell et al. (2000) em relação à dinamização da cadeia produtiva do vinho e da economia local.

A receita oriunda das taxas de visitação em si não parece ser um elemento financeiro importante para a economia das vinícolas, sendo amplamente superada pela receita da comercialização de vinhos e outros produtos. Outro aspecto que merece ser mencionado diz respeito à natureza e características das diferentes atividades identificadas - visitações, degustações, harmonizações, refeições, cursos, dentre outras -, que procuram informar não apenas sobre as condições de produção ou especificidades organolépticas dos vinhos, mas também tendem a reforçar conteúdos relacionados à cultura regional, reforçando aspectos da identidade local que fortalecem este destino turístico. Contudo, a ausência de dados sistematizados sobre o volume e o perfil de visitantes a estas vinícolas impede uma compreensão mais aprofundada de quais grupos demandam quais atividades, o que poderia ser útil para nortear ações de planejamento e gestão do enoturismo em cada propriedade.

Tendo em vista as informações apresentadas, considera-se que o objetivo deste artigo - o de descrever as práticas de visitação turística das vinícolas da Serra Gaúcha, dando especial atenção a aspectos relacionados ao histórico da visitação, à estrutura e organização receptiva, aos roteiros de visitação, aos produtos e serviços complementares, à comunicação e promoção, e à quantidade e perfil dos visitantes das vinícolas - foi alcançado. As informações aqui apresentadas podem servir como referência para a comparação das atividades enoturísticas que ocorrem em diferentes regiões, oferecendo exemplos de práticas que podem inspirar novas estratégias, bem como conferir destaque a estratégias de sucesso já adotadas. Pesquisas futuras também podem utilizar o presente trabalho como ponto de partida para a descrição das práticas de visitação turística de vinícolas localizadas em outras regiões, sobretudo nas demais regiões produtoras de vinho do Brasil. Outra sequência natural deste trabalho seria a realização de pesquisas que objetivassem abordar a temática da visitação de vinícolas sob a ótica do turista, avaliando aspectos demográficos, comportamentais e relacionados à satisfação com a experiência turística.

\section{REFERÊNCIAS}

Alonso, A., Fraser, R. A., \& Cohen, D. A. (2007). Investigating differences between domestic and international winery visitors in New Zealand. International Journal of Wine Business Research, 19(2), 114-126.

Beames, G. (2003). The Rock, the Reef and the grape: The challenges of developing wine tourism in regional Australia. Journal of Vacation Marketing, 9(3), 205-212.

Brasil, M. d. T. (2015). Manual de conceituação: Tour da Experiência. Brasília: Ministério do Turismo.

Carlsen, J., \& Charters, S. (Eds.). (2006). Global Wine Tourism: Research, Management and Marketing. Wallingford: CABI. 
Charters, S., \& Ali-Knight, J. (2002). Who is the wine tourist? Tourism Management, 23(3), 311-319.

Chiattone, M. V., \& Chiattone, P. V. (2013). Enoturismo: atrativo e ferramenta para o desenvolvimento sustentável de regiões. Revista Rosa dos Ventos, 5(4), 616-634.

Copello, M. (2015). Anuário vinhos do Brasil: panorama regiões, castas, enoturismo, produtores e dados do setor: Baco Multimídia.

Costa, L. (2010). Enoturismo e paisagem cultural: a vitivinicultura em nova proposta. Revista Rosa dos Ventos, 2(2), 116-128.

Croce, E., \& Perri, G. (2010). Food and Wine Tourism: Integrating Food, Travel and Territory. Wallingford: CABI.

Dallanhol, E. B., \& Tonini, H. (2012). Enoturismo. São Paulo: Aleph.

Dawson, H., Holmes, M., Jacobs, H., \& Wade, R. I. (2011). Wine tourism: winery visitation in the wine appellations of Ontario. Journal of Vacation Marketing, 17(3), 237-246.

Farina, C., \& Roloff, M. (2015). Conhecendo os vinhos do Brasil: Vinhos do Brasil.

Gimenes, M. H. S. G. (2012). Você tem sede de quê? Notas introdutórias sobre o enoturismo. Contextos da alimentação, 1(1), 6-15.

Grizzo, A., Burgos, C., \& Milan, E. (2014). Guia Adega vinhos do Brasil 2014/2015. São Paulo: Inner.

Hall, C. M. (Ed.). (2003). Wine, Food, and Tourism Marketing. Binghamton: Haworth Hospitality Press.

Hall, C. M., Johnson, G., Cambourne, B., Macionis, N., Mitchell, R., \& Sharples, L. (2000). Wine tourism: an introduction. In C. M. Hall, L. Sharples, B. Cambourne \& N. Macionis (Eds.), Wine tourism around the world: development, management and markets (pp. 1-23). Oxford: Elsevier Butterworth-Heinemann.

Hall, C. M., Sharples, L., Cambourne, B., \& Macionis, N. (Eds.). (2000). Wine Tourism Around the World. Oxford: Butterworth-Heinemann.

IBRAVIN. (2016a). Os vinhos produzidos no RS. Recuperado em 25 janeiro, 2016, de http://www.sobrevinho.net/paises/brasil/regioes/vinhos-produzidos-rs.

IBRAVIN. (2016b). Panorama geral. Recuperado em 25 janeiro, 2016, de http://www. ibravin.org.br/panorama-geral.php.

Johnson, G. (1998). Surveying wine tourism in New Zealand. University of Otago, Denedin.

Lavandoski, J., Tonini, H., \& Barretto, M. (2012). Uva, vinho e identidade cultural na Serra Gaúcha (RS, Brasil). Revista Brasileira de Pesquisa em Turismo, 6(2), 90-106.

Marques, C. B., \& Santos, C. H. S. (2012). A Rota do Vale dos Vinhedos e a sua Economia Local. Revista Turismo \& Desenvolvimento, 11(1).

Mitchell, R. D., \& Hall, C. M. (2003). Seasonality in New Zealand Winery Visitation. Journal of Travel \& Tourism Marketing, 14(3-4), 155-173.

Mitchell, R. D., Hall, C. M., \& McIntosh, A. (2000). Wine tourism and consumer behavior. In C. M. Hall, L. Sharples, B. Cambourne \& N. Macionis (Eds.), Wine tourism around the world: development, management and markets (pp. 115-135). Oxford: Elsevier Butterworth-Heinemann.

Peris-Ortiz, M., Rama, M. d. l. C. D. R., \& Rueda-Armengot, C. (Eds.). (2015). Wine and Tourism: A Strategic Segment for Sustainable Economic Development. Cham: Springer International Publishing.

Silva, L. F. d. M. e. (2008). De celeiro a cenário: vitivinicultura e turismo na Serra Gaúcha. (Mestrado em Geografia Humana), Universidade de São Paulo. 
Tonini, H. (2007). Estado e turismo: políticas públicas e enoturismo no Vale dos Vinhedos. (Mestrado em Turismo), Universidade de Caxias do Sul, Caxias do Sul.

Tonini, H., \& Lavandoski, J. (2011). Enoturismo: experiências e sensacões no Vale dos Vinhedos - RS. Turismo em Análise, 22(1), 25-43.

Valduga, V. (2007). O processo de desenvolvimento do enoturismo no Vale dos Vinhedos. (Mestrado em Turismo), Universidade de Caxias do Sul, Caxias do Sul.

Valduga, V. (2012). 0 desenvolvimento do enoturismo no Vale dos Vinhedos (RS/Brasil). Cultur - Revista de Cultura e Turismo, 6(2), 127-143.

Valduga, V., \& Valduga, M. (2016). The experience of wine tourism in Vale do Vinhedos - Rio Grande do Sul - Brazil. In M. Peris-Ortiz \& M. d. l. C. D. R. Rama (Eds.), Wine and Tourism: a strategic segment for sustainable economic development (pp. 71-85). Cham: Springer.

Vale dos Vinhedos. (2017). O Vale. Recuperado em 20 jan. 2017, de http://www.valedosvinhedos.com.br/vale/index.php.

Vinícola Aurora. (2017). Sobre a Aurora. Recuperado em 20 jan. 2017, de http://www. vinicolaaurora.com.br/.

Vinícola Garibaldi. (2017). A Cooperativa. Recuperado em 20 jan. 2017, de http://www. vinicolagaribaldi.com.br.

Zanini, T. V. (2007). Enoturismo no Brasil: um estudo comparativo entre as regiões vinícolas do Vale dos Vinhedos (RS) e do Vale do São Francisco (BA/PE). (Mestrado em Turismo), Universidade de Caxias do Sul, Caxias do Sul.

Zanini, T. V., \& Rocha, J. M. d. (2010). O enoturismo no Brasil: um estudo comparativo entre as regiões vinícolas do Vale dos Vinhedos (RS) e do Vale do São Francisco (BA/PE). Turismo em Análise, 21(1), 68-88.Recebido em: 05/05/2016.

Recebido em: 22/01/2017

Aprovado em: 11/10/2017

\section{CONTRIBUiçÃo}

Virgínia Aparecida Castro: Iniciativa, idealização, coleta de dados em campo e REDAÇÃO FINAL.

Glauber Eduardo de Oliveira Santos: IDEALIZAÇão, ELABORAÇÃo do INSTRUMENTO DE COLETA, ANÁLISE DE DADOS E REDAÇÃo FINAL.

Maria Henriqueta Sperandio Garcia Gimenes-Minasse: ConteXtuAlizAÇÃo TEÓRICA E REDAÇÃO FINAL.

Janaina de Moura Engracia Giraldi: Contextualização teóRICA e REDAÇÃo FINAL. 